\title{
Recognition and precarious mobilities: The experiences of university students from a refugee background in Australia
}

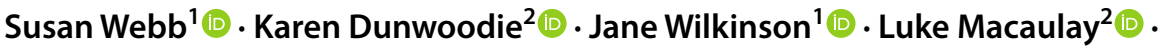 \\ Kristin E. Reimer ${ }^{1}$ (1) Mervi Kaukko ${ }^{3}$ (i)
}

Accepted: 16 September 2021 / Published online: 25 September 2021

(c) UNESCO Institute for Lifelong Learning and Springer Nature B.V. 2021

\begin{abstract}
This article employs the concepts of recognition and precarious mobilities to understand university education for people from a refugee background. The authors draw on their ongoing qualitative longitudinal narrative enquiry exploring the experiences of 22 students in Australia from asylum-seeking backgrounds during their threeyear study for a Bachelor's degree. Theories of recognition informed by the work of Axel Honneth and Nancy Fraser provide a conceptual framework for analysing the students' experiences in navigating government and institutional policies and practices which often fail to recognise the unique needs of this distinct group. Few higher education institutions fully acknowledge the educational capital and transnational understandings that students from refugee backgrounds develop through navigating precarious mobilities. Instead of receiving recognition for these assets, such students often feel they do not belong in higher education in the host society. Thus, belonging, an essential component in supporting their success in higher education and settlement, is undermined. To appreciate how university practices are informing student experiences, the authors explore two competing discourses: "the education of international students is Australia's third-largest export" on the one hand, and "higher education should be made available to all who can benefit from it" on the other.
\end{abstract}

Keywords Refugee education · Higher education - Theories of recognition · Adult education · Asylum seekers · Australia

\section{Résumé}

Reconnaissance et mobilités précaires : expériences d'étudiants issus de milieux de réfugiés en Australie - Cet article s'appuie sur les concepts de reconnaissance et de mobilités précaires pour comprendre l'enseignement universitaire destiné à des

Susan Webb

susan.webb@monash.edu

Extended author information available on the last page of the article 
personnes issues de milieux de réfugiés. Les autrices s'appuient sur l'étude narrative qualitative longitudinale qu'elles mènent actuellement et qui porte sur les expériences vécues en Australie par 22 étudiants issus de milieux de demandeurs d'asyle durant leurs trois années d'études en cursus de bachelor. Les théories de la reconnaissance orientées par les travaux d'Axel Honneth et de Nancy Fraser leur fournissent un cadre conceptuel pour analyser les expériences qu'ont vécues ces étudiants face à des politiques et pratiques gouvernementales et institutionnelles qui omettent souvent de reconnaître les besoins uniques du groupe particulier qu'ils forment. Peu d'établissements d'enseignement supérieur reconnaissent pleinement le capital éducatif et les notions transnationales qu'acquièrent les étudiants issus de milieux de réfugiés au travers de mobilités précaires. Loin d'être reconnus pour ces acquis, ils ont souvent l'impression de ne pas être à leur place dans l'enseignement supérieur de leur société d'accueil. Par conséquent, le sentiment d'appartenance, élément essentiel pour les aider à réussir dans l'enseignement supérieur et à s'installer, s'en trouve affaibli. Pour évaluer la façon dont les pratiques universitaires façonnent les expériences vécues par les étudiants, les autrices se sont penchées sur deux discours concurrents : d'une part, « l'éducation des étudiants internationaux est le troisième secteur d'exportation en Australie » et d'autre part, « l'enseignement supérieur devrait être rendu accessible à tous ceux qui peuvent en profiter ».

\section{Introduction}

International organisations such as the United Nations are calling on universities to play a role in supporting the 2030 Agenda's education-related Sustainable Development Goal (SDG 4) of increasing access to education for all throughout their life course (UNHCR 2019, UN 2015). Yet many nations, including Australia, where the study presented here is being conducted, have adopted ambivalent approaches to mobile populations seeking to access their higher education provision. While international student mobility is encouraged for its economic benefits - "the education of international students is Australia's third-largest export, behind only iron ore and coal" (Universities Australia 2017), borders are tightened to restrict the mobility of people from a refugee background (Gerrard 2017). ${ }^{1}$

This article focuses on access to higher education for members of the second group - students from refugee backgrounds. We include verbatim statements from students from asylum-seeking backgrounds in Australian universities. Their responses to our questions emerged from a second wave of interviews we conducted with them as part of an ongoing qualitative longitudinal narrative enquiry in which we are following 22 students studying for their Bachelor's degree. University students are a distinct and scarcely researched group within the category of forced migration. Asylum seekers' university experiences have rarely been studied because they are often marginalised in university data collection records, with the

\footnotetext{
1 Terminology such as "refugee", "asylum seeker" etc. is of particular importance in this context, and is addressed at the end of this introductory section.
} 
consequence that they are hard to reach and not recognised as having distinctive needs (Lambrechts 2020).

In this article, we explore students' perceptions as they attempt to navigate government and institutional policies and practices in Australian higher education. The conceptual framework of our analysis is based on theories of recognition developed by Axel Honneth (1995) and Nancy Fraser (2000). We investigate how competing notions of international student mobility feeding "Australia's third-largest export industry" (Universities Australia 2017) on the one hand, and the view that opportunities to join "higher education should be made available to all who can benefit from it" (Gurría 2009) on the other are being played out in Australian universities in relation to the educational needs of asylum-seeking students. Through giving voice to students' views, this article critically reflects on universities' potential to realise and develop their role in building a more inclusive educational experience for all.

\section{Terminology}

As mentioned earlier, in this context, terminology matters considerably. The term refugee more generally refers to someone who has been forced to leave their own country and requires protection by the country they have arrived in. Here, they seek asylum, hoping to be granted refugee status, which in Australia refers to official recognition of being eligible for this protection.

Internationally accepted definitions are provided by the 1951 Convention relating to the status of refugees and made universal by its 1967 Protocol (UNHCR 2011). Here, a "refugee" is defined as:

a person who is outside his or her country of nationality or habitual residence; has a well-founded fear of persecution [...] and is unable to avail himself or herself of the protection of that country, or to return there, for fear of persecution (ibid., p. 3).

Though the term "asylum seeker" as such does not occur in the Convention, what is central to this definition (and relevant to our study) is that an asylum seeker is a person who has applied for protection as a refugee and is awaiting the determination of their status (RCOA 2019). Correspondingly, having the status of asylum seeker presents challenges for those trying to continue their education beyond secondary schooling (UNHCR 2017).

An umbrella term (which also does not occur in the Convention itself) is "persons of concern". It denotes "asylum-seekers; refugees; stateless persons; the internally displaced; [and] returnees" (UNHCR 2006, p. 18).

\section{The research context}

The broader setting of the study we are presenting here is the ongoing global flow of refugees and asylum seekers, with the United Nations High Commissioner for Refugees (UNHCR) online database estimating at the end of 2020 that more than 
80 million people are on the move as refugees or "persons of concern" (UNHCR 2020). In 2018, only three per cent of refugees globally were attending university (UNHCR 2019, p. 7) compared to a country average of 39 per cent in 2019 (World Bank 2020). In terms of research, much of the focus to date has been on student support practices of universities in highly developed European countries, including the United Kingdom (UK), and in other English-speaking countries and regions such as Australia and North America, although countries in developing regions are grappling with similar issues (Unangst et al. 2020). Whilst undoubtedly there is a need to study the experiences of people in protracted refugee situations in developing regions, researching the experience of students seeking asylum in high-income countries remains valuable, since this provides understanding about the practices of those institutions that approach refugees in camp contexts to offer higher education at a distance (Ramsey and Baker 2019).

An emerging corpus of work from Europe and English-speaking nations in other world regions has revealed the diverse elements of refugees' and asylum seekers' settlement in their host nations - the strategies they develop, the challenges they experience and the actions of higher education institutions and other non-state actors (Jungblut et al. 2020; Unangst et al. 2020).

\section{Asylum-seeking university students in Australia}

Our article contributes to this emerging body of research by exploring the opportunities, risks, obstacles and dilemmas encountered by asylum-seeking students in their quest to access and participate in Australian higher education. We build on findings from previous research which examined the experiences of such students in their first year of university (Dunwoodie et al. 2020). We complement those findings with the same students' experiences of their second year of higher education, which we investigated in a second wave of interviews for the same longitudinal study. Participants" responses in both waves highlight the risks and frustrations students from asylum-seeking backgrounds find themselves subjected to and the struggles and strategies they experience in coming to terms with the universities' attempts to balance notions of educational support for disadvantaged students within an increasingly competitive, internationally oriented, yet strongly regulated public sector.

To comprehend the current climate within Australian universities it is important to understand that Australia - like the UK, but unlike many other countries in Europe - operates a two-tier system with respect to how students from a refugee background can access higher education (Lenette et al. 2019). In Australia, students from asylum-seeking backgrounds who are over 18 years old and have not been awarded full protection or are awaiting refugee status determination are classified as "international students". Therefore, they do not qualify for the same services and funding support as disadvantaged domestic students or others from refugee 
backgrounds who entered Australia through the Humanitarian Program ${ }^{2}$ and have already been granted protection. This means that asylum-seeking students must pay "international student” fees.

As Marie-Agnès Détourbe and Gaële Goastellec (2018) have shown in relation to England and Germany, different assemblages of asylum, welfare, citizenship and higher education policies lead to different rights and spaces of opportunity in higher education for students from refugee backgrounds. In Australia, access to higher education for asylum-seeking students exists only at the margins (Harvey and Leask 2020). The structural possibilities for students from refugee backgrounds to access and experience higher education are determined by their administrative positioning between not yet being recognised as humanitarian migrants with rights similar to other domestic citizens on the one hand and being acknowledged as people in need of protection but only accorded limited welfare rights on the other hand.

When asylum seekers in Australia are recognised as being in need of protection as refugees, they are placed on short-term bridging $^{3}$ or temporary protection ${ }^{4}$ visas. This leads to a situation in which many asylum seekers suffer precarious, liminal and peripheral conditions with regard to resettlement. These conditions include protracted refugee determination timelines, often taking several years, loss of all government support funding once the student enrols in full-time study and limited access to formal English language programmes. Additionally, the very nature of the temporary protection and bridging visas means that they may be revoked should the Australian Federal Government's assessment be unfavourable (DOHA 2019).

\section{Literature review: refugees and higher education}

Recent research has shown that recognition of these difficult circumstances is not sufficiently taken into account by the Australian higher education sector (Dunwoodie et al. 2020; Hartley et al. 2018; Stevenson and Baker 2018). The distinct needs of people from refugee and asylum-seeking backgrounds are not always fully understood by everyone involved, despite an increasing number of Australian universities offering scholarships to students from these backgrounds (see, for example, Deakin CREATE 2020), drawing usually on alumni or other financial sources, rather than federal government funding. In exploring how these students experience and negotiate higher education, this article supports Alexander Betts and Paul Collier's

\footnotetext{
2 Australia's "Humanitarian Program for refugees and those in refugee-like situations" was established in 1977. Its annual quota system offers resettlement opportunities in Australia to refugees and humanitarian entrants, e.g. due to UNHCR referral (Phillips 2017).

3 A short-term bridging visa allows holders to stay in Australia lawfully while they make arrangements to leave, finalise immigration matters or wait for an immigration decision. A bridging visa is a temporary visa which permits people to stay in Australia after expiry of their current substantive visa (any temporary visa other than a bridging visa) and while their substantive visa application is being processed.

4 A temporary protection visa (TPV) is one of two types of temporary visas available to those claiming asylum who arrive by boat. It is part of the Australian government's current policy that people who come by boat and claim asylum should not be given permanent protection. The TPV provides protection for three years and a safe haven enterprise visa (SHEV) protection for five years.
} 
(2017) call for a refocusing of refugee policies by providing more understanding of the spaces of opportunity for refugees in relation to different configurations of welfare and citizen policies and the interpretation and implementation of these policies by higher education institutions.

To date, drawing mainly on studies in high-income countries, the relevant literature has highlighted the lack of recognition of students from refugee backgrounds. These studies stress that the prior experiences and distinctive needs of asylum-seeking and refugee students are mostly (in)validated and (mis)recognised by institutions and governments (Mangan and Winter 2017). Such misrecognition compounds the effects of the precarious educational journeys undertaken by these students, so that they experience many of the same difficulties with regard to educational achievement as other minority or disadvantaged groups. These challenges include interrupted education, poverty, and language and cultural dissonance with higher education study (Earnest et al. 2010; Hartley et al. 2018; Joyce et al. 2010; Naidoo et al. 2015). Often having experienced long and complicated journeys to higher education (Morrice 2009), such students are "super-disadvantaged" (Lambrechts 2020); their separate and distinct support needs are often unrecognised by higher education institutions (Stevenson and Willott 2007) and therefore fail to be addressed.

Few higher education institutions fully acknowledge the educational capital and transnational understandings that students from refugee backgrounds develop through navigating precarious mobilities. Instead of receiving recognition for these assets, such students often feel they do not belong in higher education in the host society; they experience mental discomfort, which Linda Morrice (2013) refers to as cognitive dissonance between their sense of self and the ways in which they are identified by others as they try to engage in their studies. Thus, belonging, an essential component in supporting their success in higher education and settlement, is undermined (Lenette et al. 2019). While research has identified the resilience of students from a refugee background and noted the strengths of their ambitions when given opportunities, too often the experiences and needs of these students are homogenised as deficiencies in higher education (Morrice 2013; Naidoo et al. 2018). University practices focus on student deficits rather than strengths, and they fail to recognise the value of refugees' prior experiences (Molla 2020; Perry and Mallozzi 2011). Policy disconnects also occur when language preparation and educational support are provided at levels too low for integrating refugees into higher education (Lenette et al. 2019; Streitwieser et al. 2017).

Furthermore, refugees accessing higher education have to struggle to overcome the informational barriers to procuring academic guidance and support to navigate educational pathways (Bajwa et al. 2017). Crucially, they also experience financial precarity. Since their legal status and membership of a place is uncertain; even those who do well in the school system in Australia and are selected for entry into the university system often decline the places they are offered because they cannot afford to enrol as an international student (Hirsch and Maylea 2016). Moreover, whilst Australia has a relatively generous refugee settlement programme, there is a mismatch between the multicultural initiatives at federal and state level and the relative invisibility of federal and state policies to promote multiculturalism at the sectoral level of higher education (Molla 2020). Many universities find that government policies 
that treat students from refugee and asylum-seeking backgrounds as high-fee-paying international students restrict their institutional ability to implement multicultural policies. Consequently, universities have developed scholarship schemes funded from non-government sources to mitigate these effects for asylum seekers. Nevertheless, the participation of students from asylum-seeking backgrounds is very limited because of these policy misalignments (Molla 2020; Webb et al. 2019).

In spite of the diversity and growth of literature in this field, there is still a research gap. Many studies have focused on how students from refugee backgrounds access higher education, rather than on the experiences of the few who secure university places and complete Bachelor degrees (Ramsey and Baker 2019). This article contributes to filling this research gap by addressing the question of how students from asylum-seeking backgrounds are experiencing higher education.

\section{Theoretical background: thinking about the student experience through concepts of recognition}

In our first-wave analysis of the experiences of 22 refugee and asylum-seeking students in their first year of Australian university (Dunwoodie et al. 2020) when we embarked on our longitudinal enquiry, we drew on Axel Honneth and Nancy Fraser's concepts of recognition.

According to Honneth's theory of recognition, in order to be able to act with agency, there is a human need for people to have their identity accepted in three spheres of their life: the family, civil society and the state (Honneth 1995). A sense of belonging in these spheres also associates with identity recognition and underpins positive experiences of higher education. Indeed, a sense of belonging has enabled some asylum-seeking students to view the university as a place of refuge (Fleay et al. 2019).

But as we have shown above in the literature review, students from asylumseeking backgrounds struggle financially and materially. For this reason, this article also draws on Fraser's (2000) concept of recognition, which is embedded in a theory of social justice based on parity between people for participation in social spheres. Fraser (ibid.) argues that there is no participation parity (or social justice), when people have to struggle over the distribution and redistribution of economic and material resources, because their identity as an equal is misrecognised. She contends that the identity model of recognition risks displacing, reifying and individualising the reasons why some people are excluded from fully participating in established societal structures for education, employment and political decision-making. Fraser (ibid.) argues that to redress these inequalities, institutionalised patterns of subordination need to be examined, and the economic and socio-cultural harm that stems from people's status subordination needs to be confronted. In other words, Fraser's (ibid) theory of social justice employs the concept of policy misframing to argue that injustice arises when the social policies are framed so that the effects of differences in economic, material or social circumstances on people's opportunities to participate are not recognised. In the context of this article, adopting Fraser's approach to recognition means exploring 
how institutional practices might construct or frame some types of students and social backgrounds as the norm and others as different, deficient or inferior, thereby creating divisions in the allocation of or access to university resources and students' sense of belonging and right to participate.

The concept of recognition has increasingly informed research on widening participation for students from refugee backgrounds. In their synthesis of eight studies from the UK, Australia and Malta, Doireann Mangan and Laura Anne Winter (2017) identify (in)validation and (mis)recognition of the experiences of students from refugee backgrounds in higher education as central themes. Similarly, Tebeje Molla (2020) draws on Fraser's theory of social justice and the concept of policy misframing to examine the question of the representation of refugees' interests in Australian policies at federal, state and sector level with regard to who is included or excluded from the equity project of higher education. Morrice (2013) too highlights how Fraser's conception of social justice as parity of participation reveals that the strengths students gain from their diverse experiences as refugees are not made visible in the policy discourses of higher education.

In light of these aspects of recognition, we designed our study to collect data to explore the three analytically distinct yet implicitly connected aspects of Fraser's $(2000,2007)$ theory of social justice, applying each of them to asylum-seeking university students: (1) the economic-material conditions (redistributive); (2) the sociocultural context (recognitive); and (3) the political-legal position (representative). In addition, our lens for analysis considers how identity recognition (or misrecognition) may be revealed through displays of "love", "respect" and "esteem" (Honneth $1995)$ in everyday relationships between students, their teachers and other staff.

\section{Methodology}

\section{Study design}

Our research team consists of the six authors of this article. As mentioned earlier, at the time of conducting the interviews discussed in this article, we had already completed the first wave of our research (see Dunwoodie et al. 2020), which was part of a three-year longitudinal study designed to follow the typical student journey from initial entry to completion of a Bachelor's programme in higher education. Of course, not all students complete their degrees in three years, however, the research was designed to collect data annually using semi-structured qualitative interviews at three points in their higher education journey.

Our analysis of the first-wave interviews (ibid.) had concentrated on providing understanding of the students' experiences of getting into university and their first year of study, whilst the second-wave interviews (the focus of this article) explored the students' experiences in the middle of their Bachelor programme. The purpose of the second wave was to confirm and corroborate results from the first round of interviews, while turning to the question: How are students experiencing their degree study? 


\section{Participants}

Our original study sample comprises 22 students from asylum-seeking backgrounds whom we identified through snowball sampling. At the time of our firstwave interviews, they were studying at seven universities in one state in Australia. During both the first-wave and the second-wave interviews, our focus was on the students' perceptions of their experiences rather than institutional comparisons. Nevertheless, their experiences do of course also highlight perceptions of institutional differences.

When we conducted our first-wave interviews, the average age of the students was 22. Nine participants identified as female and 13 as male. Countries of origin varied greatly, with the majority of the participants coming from Iran, Afghanistan or Pakistan. All were first-year undergraduate students starting out on their Bachelor programme, and their fields of study included engineering, science, nursing, commerce, psychology and education. Nineteen of the 22 students were on full-fee university scholarships and in some instances received an annual bursary of up to AUD 8,000. Due to many of the participants still being on different kinds of temporary visas, we have kept demographic information at a general level (see Table 1).

In both waves, we conducted the interviews in English, either face-to-face or online (i.e. using Zoom or Skype). All interviews were recorded and transcribed. First-wave interviews $(n=22)$ lasted on average 42 minutes, and second-wave interviews $(n=16)$ lasted on average 46 minutes. Again, in both waves, we collected the students' responses thorough in-depth semi-structured interview protocol, using a core set of questions, but we adapted these depending on the direction of the interview. This enabled our participants to drive the responses according to their experiences, context and comfort level. Second-wave data were collected 12 months after the first-wave interviews. Voluntary participation was stressed with all participants throughout the research process, to ensure they understood that they had the right to withdraw from the study at any time without negative consequences.

\section{Longitudinal research both reveals and is challenged by participants' uncertain legal status}

Conducting a long-term study of these students' experiences over time involves recognising the fluid and dynamic context in which they are struggling to find footholds. Changes in the external policy environment can occur at any time, affecting the students' economic and material circumstances and their legal-political position in the country, with consequences for university attrition. Six of our original participants did not participate in the second wave of interviews, for various reasons. Some did not want to continue as a participant in the study, others may have changed their contact details which meant that we were unable to locate them for follow-up. Some had also ceased to study at their original university. Thus, in the second wave which informs this article, we were able to conduct interviews with only 16 of the 22 students who had been in the first-wave interviews. 
Table 1 Demographics of study participants

\begin{tabular}{|c|c|c|c|c|}
\hline Participant $^{\mathrm{a}}$ & Gender & Family status $^{\mathrm{b}}$ & $\begin{array}{l}\text { Migration } \\
\text { status }^{c} \text { W } 1\end{array}$ & $\begin{array}{l}\text { Migration } \\
\text { status }^{c} \\
\text { W } 2\end{array}$ \\
\hline
\end{tabular}

\begin{tabular}{|c|c|c|c|c|}
\hline Rezas & M & UAM & A & $\mathrm{T}$ \\
\hline Mohammed & M & FAM & A & $\mathrm{E}$ \\
\hline Sharnaz & $\mathrm{F}$ & FAM & A & $\mathrm{E}$ \\
\hline Sam & M & UAM & $\mathrm{T}$ & $\mathrm{T}$ \\
\hline Navid & M & FAM & $\mathrm{T}$ & \\
\hline Ahmed & M & UAM & $\mathrm{P}$ & $\mathrm{P}$ \\
\hline Fatima & $\mathrm{F}$ & FAM & A & $\mathrm{T}$ \\
\hline Nima & $\mathrm{F}$ & FAM & A & $\mathrm{T}$ \\
\hline Omid & M & FAM & $\mathrm{P}$ & \\
\hline Danush & M & UAM & A & $\mathrm{T}$ \\
\hline Munjid & M & FAM & A & \\
\hline Peter & M & UAM & $\mathrm{S}$ & \\
\hline Baraz & M & UAM & $\mathrm{P}$ & $\mathrm{P}$ \\
\hline Fara & $\mathrm{F}$ & FAM & $\mathrm{P}$ & $\mathrm{P}$ \\
\hline Manu & M & UAM & A & \\
\hline Sharlim & $\mathrm{F}$ & FAM & A & $\mathrm{T}$ \\
\hline Yasmin & $\mathrm{F}$ & FAM & A & $\mathrm{T}$ \\
\hline Roshan & M & FAM & A & $\mathrm{E}$ \\
\hline May & $\mathrm{F}$ & FAM & A & \\
\hline Ali & M & FAM & A & A \\
\hline Ruby & $\mathrm{F}$ & FAM & $\mathrm{P}$ & $\mathrm{P}$ \\
\hline Jules & $\mathrm{F}$ & FAM & $\mathrm{A}$ & $\mathrm{T}$ \\
\hline
\end{tabular}

Notes: $n=22$ Wave 1 [W 1], $n=16$ Wave 2 [W 2] interviews

${ }^{a}$ Actual names have been replaced by pseudonyms to protect participants' anonymity.

${ }^{\text {b}}$ Family status: UAM = arrived in Australia as an unaccompanied minor; FAM = arrived in Australia with at least one other family member

${ }^{\mathrm{c}}$ Visa status: $\mathrm{A}=$ asylum application submitted, awaiting refugee status determination; $\mathrm{E}=$ refugee status denied and awaiting an appeal, bridging visa granted; $\mathrm{P}=$ permanent protection granted; $\mathrm{T}=$ temporary protection (3-year) or $\mathrm{S}=$ safe haven enterprise (5-year) visa granted

\section{Mapping the students' situations in their second year at university}

Besides using the second-wave interviews to confirm and corroborate results from the first round of interviews, as a step in triangulating the data as suggested by Norman Denzin (2015), the main focus of the second-wave interviews was to explore the participants' reflections on being at university for nearly two years. We were interested to find out and understand what strategies they had used to 
assist them in settling into life as a student. What were some of the challenges? Who or what services (if any) supported them in their studies?

\section{Changes in representative recognition}

These second-wave interviews revealed considerable changes in one aspect of the students' recognition by the Australian state; that is, in their political-legal recognition and the potential this created to increase (or decrease) what Fraser $(2000,2007)$ refers to as their representative recognition. ${ }^{5}$ Of the 16 participants we interviewed in the second wave of our tracer study, four were still in a state of limbo: one had still not had their refugee status determined (after seeking asylum in 2013), and three were subject to ongoing legal argument regarding their refugee status applications. Among the other 12 participants whom we interviewed in the second wave, four had been granted permanent protection, and one awarded temporary protection, prior to our first-wave interviews, and all had applied for citizenship. Between the first and second waves of interviews, seven participants (the eighth participant was awarded temporary protection prior to first-wave interviews) had had positive refugee status determination and had since been granted temporary protection (3-year) or safe haven enterprise (5-year) visas.

Furthermore, seven students in our original sample, of whom five were still participating when we conducted our second-wave interviews, had arrived in Australia as unaccompanied minors. Two of these five had been granted protection visas, hence were able to travel outside Australia to visit family, whilst those remaining on temporary protection or bridging visas had not had any physical contact with their families for at least eight years. The remaining nine second-wave participants had arrived in Australia with at least one other family member (see Table 1).

Clearly, although representative recognition had improved for some students in our sample in that they had been given the right to stay permanently or temporarily in Australia, several were still studying under precarious conditions not knowing whether they would be able to make a life in Australia after their degree, or even be permitted to complete the degree. Even those refugees with permanent protection have more limited rights and responsibilities compared to those with citizenship; they have limited overseas travel rights, and cannot vote or be employed by the government or defence forces. Other domestic or international students would not be subjected to the experience of such political-legal precarity. It is not surprising that the dynamics of this precarious situation framed the study experiences of these students in our data analysis below.

\footnotetext{
5 Fraser's concept of representative recognition refers to the formal legal status that enables people to fully participate in a country's federal or state decision-making processes. In Australia, different visa categories confer different representative recognition regarding people's rights and responsibilities: citizenship confers recognition that a person has the responsibility to participate in the democratic processes by voting and the right to be represented by elected members of the government in the decisions being made about the country. Permanent residents, temporary residents and asylum seekers awaiting decisions about their legal status do not have this representative recognition.
} 


\section{Data analysis}

As mentioned earlier, the research question we were interested in 12 months after our first-wave interviews was How are students experiencing their degree study? To answer this question, we continued to frame our analysis with recognition theory, but found that new codes emerged inductively from the data. In our analysis of students' responses from both waves of interviews, we therefore employed both deductive and inductive approaches. This resulted in our identifying three core themes regarding (1) participants' understanding and interpretation of any barriers and concerns; (2) their sense of identity and belonging; and (3) their experiences of connectedness and support.

\section{Findings}

Our analysis of students' views as they were completing their second year at university identified many challenges similar to those they had experienced during the first year of their studies (Dunwoodie et al. 2020). Notably, however, despite these continuing challenges, the second-wave data revealed numerous instances of participants feeling more settled in the universities because they had a been able to build up a sense of belonging and support. Whilst increased familiarity over time may have contributed to this increased feeling of belonging, students specifically identified particular university practices which had helped them. They also recommended that some universities should consider performing these practices better in order to support asylum-seeking students more effectively and compassionately.

As mentioned earlier, our subsequent analysis of the data focused on three core themes which had inductively emerged from the students' responses:

(1) Continuing misrecognition - barriers and concerns

(2) Emerging socio-cultural (recognitive) recognition - identity and belonging

(3) Growing parity of participation - connectedness and support.

In the next sections, we address each of these core themes in turn.

\section{Continuing misrecognition - barriers and concerns}

When asked to reflect on their experiences at the mid-point of their degree study, many of our participants identified a range of issues similar to the barriers and concerns experienced during their first year of study. These barriers and concerns included the ongoing precarity of their visa situation and the impact of the Australian government's policies on their lives and studies, lack of family support through being separated from their relatives, and mental health issues. These multiple difficulties resulted in continuing anxieties and a general distrust of all authorities. This distrust had the effect of increasing the cognitive dissonance between the 
universities' treatment of asylum-seeking students as "international students" who should be financially independent and the students' awareness that they had distinct needs in undertaking university study which could not be likened to the needs of other international students. In other words, they experienced a continuing lack of recognition of their right to higher education.

Even though seven participants had seen a "positive" change in their visa status since they began their university courses, their new temporary protection visa status still prevented them from travelling outside Australia, while their families were unable to travel to Australia. This level of legal recognition restricted what Fraser (2000) terms the participation parity of participants. ${ }^{6}$ Its impact was particularly difficult for those who had arrived as unaccompanied minors, as expressed by Rezas and Sam: ${ }^{7}$

"My visa, I haven't seen my family for several years, [and I] miss my family, they miss me; they ask me to come but I can't go [...] it hurts me a lot and it pushes me back every time in a corner." (Rezas, W 2)

"So we don't have family - most of us don't have our family here and sometimes you actually get pressure by your family because it is sometimes like most of us have family to support and you've got to look after your family and sometimes you've got some sort of depression and anxiety that you need help." (Sam, W 2)

Restrictions on international movement also limited the extent to which students could fully engage in the internationalised Australian higher education curriculum, with international mobility as its norm. For instance, students could not participate in study abroad programmes. Moreover, not only did they lack the immediate support that families can usually provide, sometimes it was the students who were providing economic support to their family overseas.

Additionally, even those who had arrived with family experienced conflict and increased stress related to their subordinate legal, socio-cultural and economic positions. This was evidenced as the students were becoming older, were able to work part-time, became more proficient at English and were more knowledgeable about navigating "Australian systems", such as legal, medical and other government bureaucracies. Hence, they were increasingly assuming "parenting" roles and overall family responsibility:

"Last year was absolutely horrendous. It really did ruin me, mentally [...] when I struggled a lot I just felt alone, and no one could help me. When I did try and ask people for help [...] I didn't get any, which I'm very disappointed

\footnotetext{
${ }^{6}$ Fraser's notion of participation parity refers to the parity or differences conferred on people to participate in a country's social and legal-political system. Since none of the participants were citizens, their participation in Australian society was restricted in relation to travel, voting and representation in federal and state parliaments; employment in government and the defence services and access to post-school education and healthcare.

7 These participant names are pseudonyms, and W 2 refers to the second wave of interviews.
} 
about and I really wish that XXXX University wouldn't have done that to me because [...], I was sick [...] struggling so much last year." (Sharlim, W 2)

The economic and legal precarity of their asylum-seeking families meant that many students had the double-edged problem of trying to manage their studies alongside handling their families' struggles for economic resources and legal recognition. Coping with these economic and legal precarities caused immense stress and anxiety especially when students were denied refugee status. For some, this meant that they experienced the loss of their study rights, only to have these rights reinstated upon appeal when granted temporary protection. Fatima was one such student:

"But unfortunately the government - the current government and this policy it's - I'm just looking for the most suitable word to say it. It's not human treated - they don't treat us as human - nope, because I think all human have right to study and education is everybody right." (Fatima, W 2)

Fourteen of the sixteen participants in this second wave of our study were the first in their families to attend university. Many also had a limited understanding of how universities work. When asked to reflect on their first year at university, many students spoke of being afraid and uncertain:

"I was so afraid in my first year, that oh my god, am I reading the right articles, is my method of taking notes, is it correct, am I not missing something. For instance, how many assignments do we have, all those sort of stuff where you can help each other." (Rezas, W 2)

Like other "first-in-family" students, the participants in our study often did not understand the academic expectations of university study and they did not have others in their family or community networks whom they could learn from. By their second year, they were aware of the gaps in their initial knowledge and able to identify what processes and support systems the universities could have provided to enable them to fare better:

"When I started here, I wasn't very clear and I did not exactly know how to learn and where to go to seek for help to help me learn." (Mohammed, W 2)

"I think one of the main things is the counselling, internal counselling in terms of like career counselling. Because when you come out of the high school and going to uni, you are at sort of age and don't have the experience, especially the asylum seeker students they don't have many graduates from their families, like they are working class. [...] it means that if family, their parents don't have that knowledge, they are not much educated to direct [...] what to study and what would it mean for your future." (Danush, W 2)

Whilst these uncertainties about how to be a university student are views that are often also expressed by other students from disadvantaged backgrounds, unlike other first-in-family domestic students, the cultural dissonance experienced by students from asylum-seeking backgrounds between their previous learning and university study was compounded by their economic and legal precarity. They experienced 
super-disadvantages (Lambrechts 2020), which affected their perception of their social-cultural inclusion or right to be in higher education.

\section{Emerging socio-cultural (recognitive) recognition - identity and belonging}

In spite of the continuing concerns voiced by many of the students, some participants felt that they had become more confident and comfortable accessing services within the university system:

"So, right now I have a full access to mental health service here and I do see psychology every - once every month [...] she has been very supportive and I've been seeing her for about two years now." (Mohammed, W 2)

These more confident students expressed a new identity as university students who now feel they belong in this new space in a new country:

"[People at my university] never thought that the girl which came by boat one day she can improve herself and to be in this position. They thought I am, as I say I am international I'm doing my best because I want to just study, well I'm studying with lots of other situation which happen to my family and myself." (Sharnaz, W 2)

These more confident students stated that when they no longer needed to explain their differences to others in the university, they felt that they belonged; in other words, they had achieved what Fraser (2000) calls socio-cultural (recognitive) recognition: ${ }^{8}$

“It is, it is, it is a big different [...] when I'm at uni I feel myself - I'm at home. This is how safe I feel [...] everybody know me I'm [Fatima], I'm a nursing student. All the staff know me, all the student know me. I don't have to explain. Which when I'm outside sometimes you have to explain who you are and how you came." (Fatima, W 2)

However, not all students were confident that staff and students in their university were supportive or understanding of their situation. Rezas recalled his experience trying to access student services in first year and commented that even now in his second year, he still found it difficult to approach the university for help:

"But first year of my degree, whenever I'd go to the student services there was this issue of where to put me, they would consider me as international student and I wouldn't consider myself as international student, then there was this confusion what to do with me; so there was sort of trouble [...] That I've come by boat, this and this, I'm in this visa, I have this scholarship, so it's really not worth it to go and explain for them everything from the start." (Rezas, W 2)

\footnotetext{
${ }^{8}$ Fraser's concept of socio-cultural (recognitive) recognition refers to the recognition or acceptance people display towards individuals from different cultures and experiences or with different values and identities.
} 
Rezas appeared to feel that the university staff continued to misrecognise the distinctiveness of his enrolled status and study rights as a person seeking asylum who was neither a typical high-fee-paying international student, nor a domestic student from a disadvantaged background, for whom the equity programmes and scholarship schemes are normally designed.

\section{Growing parity of participation - connectedness and support}

Increased familiarity with the campus and with the expectations of university study meant that a number of these second-year students felt more settled compared to their first year. Students acknowledged that they had needed guidance from the support services of the university in order to develop their understanding of academic work:

"I think [...] very important focus of the services helping mostly in first year to make life much easier for students in terms of everything from university website to what services are available and to help them with every part of university, referencing and everything and showing them this is the library and help you with this, help you with this, help you with this." (Rezas, W 2)

With this growing familiarity, they were able to participate more equally and make use of the services available to support all students:

"So second year from a university perspective I can tell that this year it's like like everything gone smoother compared to last year. Like I am more familiar with the campus, with my studies and pretty much everything at the university. I am feeling much in a better - that I am more familiar with the staff and I can handle the situation or I can deal with the situation much better compared to last year, compared to when I first started." (Sam, W 2)

However, their mental health and well-being and the need to access relevant support services were issues that were prevalent even in the accounts of students who felt fairly settled. These students acknowledged that their needs could be better recognised by their institutions, but given their continuing precarious legal position, they were reluctant to voice their concerns. In this regard, their unwillingness to speak back to the institutions may well have reflected their lack of recognition. Using Fraser's $(2000,2007)$ terminology, arguably the (in)validation of their experiences ${ }^{9}$ could result in their feeling that they did not have the parity with other students which they needed to fully participate in the institutional processes. For example, Fatima observed:

\footnotetext{
${ }^{9}$ Fraser's concept of (in)validation refers to the way that university policies frame all non-citizens and non-permanent residents as international students and do not validate or recognise differences in the educational journeys to becoming a university student followed by those from asylum-seeking backgrounds compared to international students who are citizens of another country.
} 
"When I enter the university, I feel I'm safe. What I think about the policy I have no comment [...] Prefer not to say anything." (Fatima, W 2)

Another participant reinforced this view when stating that their experience would be greatly enhanced if the distinct needs of students from asylum-seeking backgrounds could be recognised by universities:

"[...] having a psychologist or a counsellor or someone that's more skilled in dealing with people like that. I mean they have people who went through the trauma of social violence [...] family problems but they haven't had enough experience with dealing with people like that who have good family, but they are not - they don't have that any more. So how would you deal with someone like that. It's different." (Amid, W 2).

Encouragingly, in two of the seven universities the distinct needs of these students were recognised. The practice in these universities was to assign students from asylum-seeking backgrounds to a dedicated student support advisor who was well-versed in the refugee situation and who was their first point of contact for all support, be it health and well-being, academic support, or financial and material aid. The students with this dedicated support displayed a greater "sense of belonging" and "trust" in the university:

"She [my student support advisor] has made me very comfortable in terms of I've never - I do not feel insecure or ashamed of my sexuality or my background status. She is very open minded and every time I talk to her, she makes me feel very empowered." (Mohammed, W 2)

"XXXX University has been really great in providing that support. I know some of my friends are not allowed to study part-time at other universities, but XXXX gave us the green light last year and they told us you can, if you need to, you can go ahead and work and just decrease your study load into a part-time load if you need to." (Nima, W 2)

Importantly, some universities also recognised that without economic parity with the norms expected for other students, participation of students from asylumseeking backgrounds would be severely affected. The universities that recognised the material needs of students helped them with part-time job hunting:

"[...] supports still going on from the university. They offer us a job as well. So this year I start to work with the XXXX University as Student Ambassador. Which is a paid work and just to make it easier for us to study and work at the time. And we can afford our bills basically." (Fatima, W 2)

However, students at the five institutions who did not have a dedicated and qualified student support person were still experiencing difficulties:

"[...] my first and second year I used to go to [...] support services like the faculties, like [...] faculty. And I found a lot of them, they don't even - they don't understand my experience, they don't know my story. They don't want 
to, they are not willing to listen to me and they are always in hurry, in rush so I could feel that they're comparing me with other students." (Baraz, W 2)

One of our participants expressed how he felt when he visited his faculty to ask for advice. He had arrived in Australia as an unaccompanied minor and reflected on an experience that he shared with us in both the first- and the second-wave interviews. He spoke about not having anyone to turn to and how this experience still affected him deeply today:

"Once I went to art faculty to receive help [...] before she helped me, before she listened to my challenges, she started lecturing me. She said, 'Oh [... ] you are not a serious student. Look at you, I can see your record. You have been dropping out.' [...] So, she didn't even let me talk about the situation, the challenges. And I just - I just looked at her, I cried, and I just took my laptop and left. So, I never - I never went to art faculty for help again." (Baraz, W 2)

This lack of recognition of their needs in the university is particularly difficult for those who arrived in Australia as unaccompanied minors without their families. All but one of the former unaccompanied minors in our study had been denied the right to be reunited with their families. Such students stated that they dealt with their isolation from family and lack of support inside the university by relying on support from other ex-unaccompanied minors with whom they were friends:

"I don't honestly have that kind of support. That sort of people to help me in terms of - outside of university no I don't have any people - I don't have that sort of connection but I do have friends - you know friends with the same kind of background - refugee background [...] inside your heart or inside your body and I think there should be someone in your life and in everyone's life that you know, you should have someone talk to." (Sam, W 2)

The experience of these students from asylum-seeking backgrounds clearly shows their distinct needs need to be recognised by the universities in which they are studying. Dedicated support from people who understand their situations needs to be provided continuously from the beginning of the university students' journey through to the end of the experience in order to allow trust in services to develop and avoid attrition. As trust develops among individuals, the message will spread more widely and help sustain student recognition that the university supports those from asylum-seeking backgrounds:

“[...] when I first started, I didn't know anything, everything was new, and it was very hard to reach out to those services. So, now I - now that I know support services, now that I know people and now that I know how to - how to - how to get help. So, I basically aware other students that - when they come. So, I talk to them, I let them know. I show them - I educate them about the support services [...] in the very beginning, [...] that is the hardest part, first year and second year. That two years is very important. If we 
success, then we will success, we will finish our degree. If we don't, then we'll give up, we quit. And many my friends, many of them, they quit the first and second year. Knowing they couldn't get those help [...] If in the first and second year, not in third and fourth year because that's too late. They should reach those services first and second year." (Baraz, W 2)

\section{Discussion and conclusion}

In this article, we have explored a clash between the precariousness of asylum-seeking students' trajectories and institutional practices which often (mis)recognise not only this precariousness, but also the students' skills and knowledge. Our findings show that this clash is exacerbated by the effects of frequent changes in government policies in relation to the social and financial support of asylum-seeking students provided from public funds. By being assigned to the enrolment category of "international students", these students are aligned with an international marketised discourse that recruits students from overseas. This discourse is designed to fulfil Australia's drive to export knowledge and earn fee income from students presumed to be financially independent (Harvey and Leask 2020), ${ }^{10}$ while financial independence is far from the reality of the participants of our study. With little recognition of the specific needs of university students from asylum-seeking backgrounds at national, state or sectoral level, especially in relation to their access to higher education, the outcome against these odds is that few such students successfully complete university degrees (Molla 2020). Our findings show that second-year students experience the continuing policy misalignments as stressful. These misalignments include those between the national level and the sectoral level, as well as misalignments within institutions. The legal and socio-economic subordination of this social group means that they are subjected to ongoing external pressures unlike those experienced by other groups of students. Even when asylum-seeking students had gained a place in university, they continued to face external pressures on their right to study and be legally recognised and allowed to remain in Australia. On top of this, this they experienced financial precarity such as the withdrawal of welfare funds, difficulties combining part-time work and study, and ongoing concerns for their families either in Australia or elsewhere.

The students we interviewed for this study were legally recognised as "international students", but were not legally permitted to be internationally mobile. Yet, their legal recognition as international students compounded misrecognition of the disadvantaged socio-economic contexts these students were experiencing, a "policy weakness" also discussed by Andrew Harvey and Betty Leask (2020, p. 193). The students shared many of the conditions of first-in-family students - such as financial precarity, socio-cultural differences, and a lack of access to networks familiar with Australian higher education to help ease their understanding of the cultural

\footnotetext{
${ }^{10}$ Data collection for this article occurred prior to the global COVID-19 pandemic which has halted the international mobility of all students.
} 
and academic expectations of higher education study. National and sectoral policy aligned these students with international students deemed to be financially independent, although a more suitable alignment would have been with national priority equity groups. Australian universities receive additional funding to support university access and completion of degrees by these domestic national priority equity groups, but asylum seekers are excluded from this categorisation. Consequently, this misrecognition of their circumstances and distinct needs affected our respondents' identity and sense of belonging, so that these students themselves did not always recognise their right to make use of many of those support services that were in place.

Moreover, unlike other (domestic) first-in-family students, who are often able to draw at least on some kind of resources of family, friends and community for support in an unfamiliar university setting (O'Shea 2016), students from asylumseeking backgrounds are more often alone, either having arrived as unaccompanied minors, and/or being the ones providing rather than receiving support from other family members. They are, as Agata Lambrechts (2020) argues, super-disadvantaged, and their distinct needs are still not being recognised (Morrice 2013; Mangan and Winter 2017; Ramsey and Baker 2019; Stevenson and Baker 2018).

At the sector and institutional level, however, the gradual growth in scholarships for students from these backgrounds, and in some cases the appointment of dedicated support staff, shows that there are places with promising signs of increasing recognition of the distinct needs of students who are asylum seekers. In the two institutions where dedicated staff were assigned to support students from asylum-seeking backgrounds, these students were more settled, and expressed a sense of belonging. The accounts of these students stated that such support was ensuring their success in the university and would enable them to complete their degrees. As Caroline Fleay et al. (2019) argue, supporting these students requires a collective approach in which the students and staff build trust. Arguably, such collective endeavours enable recognition of the identity of the person, and when love, respect and esteem flourish in these interactions, individual agency develops (Honneth 1995).

In conclusion, enabling access to higher education for asylum-seeking students will be facilitated when policies at different levels (national, sectoral and institutional) are aligned to support the distinct needs of this super-disadvantaged group. As Fraser $(2000,2007)$ argues, social justice in which there is participatory parity needs recognition at the legal, economic and material and socio-cultural levels. At the same time, practices to support the parity participation of students from asylum-seeking backgrounds throughout the whole of the student journey need to develop through a collective approach in which these students can recognise and identify with various service provisions and begin to trust that these services belong to them. Nevertheless, as Détourbe and Goastellec (2018) argue, the relationship between asylum, citizenship, welfare and higher education policies is complex, and the assemblages of the relevant policies need to be investigated to understand what opportunities can be provided for asylum-seeking students seeking to participate in higher education. In the case of Australia, in spite of the misalignments between these national and sectoral policies (Molla 2020), this study confirms the findings of a number of European studies (Jungblut et al. 2020; Streitwieser et al. 2017) that 
show how public universities are able to use their semi-autonomous position to recognise the distinct needs of students from refugee backgrounds, especially when they have funds from sources other than the federal government, such as from their alumni. In this way, these non-state actors are able to mitigate the restrictive effects of federal government policies, provide leadership to sectoral policies and create spaces of opportunity for refugees.

Acknowledgements The authors would like to thank the participants in this research study for giving their time generously to help us understand their experiences.

\section{References}

Bajwa, J. W., Couto, S., Kidd, S., Markoulakis, R., Abai, M., \& McKenzie, K. (2017). Refugees, higher education and informational barriers. Refuge, 33(2), 56-65. https://doi.org/10.7202/1043063ar

Betts, A., \& Collier, P. (2017). Refuge: Transforming a Broken Refugee System. Penguin Books.

Deakin CREATE (Centre for Refugee Employment, Advocacy, Training and Education). (2020). Deakin CREATE Scholarships [dedicated webpage]. Burwood, VIC: Deakin University. Retrieved 10 February 2021 from https://deakincreate.org.au/scholarships/.

Denzin, N.K. (2015). Triangulation. In G. Ritzer (Ed.), The Blackwell Encyclopedia of Sociology [online]. Malden, MA: Blackwell/John Wiley. https://doi.org/10.1002/9781405165518.wbeost050.pub2.

Détourbe, M.-A., \& Goastellec, G. (2018). Revisiting the issues of access to higher education and social stratification through the case of refugees: A comparative study of places of opportunity for refugee students in Germany and England. Social Sciences, 7(10), 186-206. https://doi.org/10.3390/socsc i7100186

DOHA (Australian Department of Home Affairs). (2019). Cancelling a visa [dedicated webpage]. Canberra: DOHA. Retrieved 20 October 2019 from https://immi.homeaffairs.gov.au/visas/cance lling-a-visa.

Dunwoodie, K., Kaukko, M., Wilkinson, J., Reimer, K., \& Webb, S. (2020). Widening university access for students of asylum-seeking backgrounds: (Mis)recognition in an Australian context. Higher Education Policy, 33(2), 243-264. https://doi.org/10.1057/s41307-019-00176-8

Earnest, J., Joyce, A., de Mori, G., \& Silvagni, G. (2010). Are universities responding to the needs of students from refugee backgrounds?. Australian Journal of Education, 54(2), 155-174. https://doi.org/ $10.1177 / 000494411005400204$

Fleay, C., Mumtaz, G., Vakili, M., Hartley, L., Macfarlane, C., \& Sayer, R. (2019). Enabling access to higher education for people seeking asylum: A collective approach. Widening Participation and Lifelong Learning, 21(2), 168-189. https://doi.org/10.5456/WPLL.21.2.168

Fraser, N. (2000). Rethinking recognition. New Left Review, 3(3), 107-120.

Fraser, N. (2007). Identity, exclusion and critique. A response to four critics. European Journal of Political Theory., 6(3), 305-338. https://doi.org/10.1177/1474885107077319

Gerrard, J. (2017). The refugee crisis, non-citizens, border politics and education. Discourse: Studies in the Cultural Politics of Education, 38(6), 880-891. https://doi.org/10.1080/01596306.2016.1227959

Hartley, L., Fleay, C., Baker, S., Burke, R., \& Field, R. (2018). People seeking asylum in Australia: Access and support in higher education. Perth, WA: National Centre for Student equity in Higher Education, Curtin University. Retrieved 10 February 2021 from https://www.ncsehe.edu.au/publi cations/people-seeking-asylum-in-australia-access-and-support-in-higher-education/.

Gurría, A. (2009). The new dynamics of higher education and research for societal change and development. Introductory remarks delivered on 5 July in Paris at the UNESCO World Conference on Higher Education. Paris: Organisation for Economic Co-operation and Development (OECD). Retrieved 24 August 2021 from https://www.oecd.org/education/thenewdynamicsofhighereducatio nandresearchforsocietalchangeanddevelopment.htm.

Harvey, A. \& Leask, B. (2020) At the policy margins: People from refugee backgrounds in Australian higher education. In L. Unangst, H. Ergin, A. Khajarian, T. DeLaquil \& H. de Wit (Eds), Refugees and higher education Transnational perspectives on access, equity and internationalization (pp. 193-205). Leiden/Boston, MA: Brill/Sense. 
Hirsch, A., \& Maylea, C. (2016). Education denied: People seeking asylum and refugees trapped in limbo. New Community, 14(355), 19-24.

Honneth, A. (1995). The Struggle for Recognition: The Moral Grammar of Social Conflicts. MIT press.

Joyce, A., Earnest, J., de Mori, G., \& Silvagni, G. (2010). The experiences of students from refugee backgrounds at universities in Australia: Reflections on the social, emotional and practical challenges. Journal of Refugee Studies, 23(1), 82-97. https://doi.org/10.1093/jrs/feq001

Jungblut, J., Vukasovic, M., \& Steinhardt, I. (2020). Higher education policy dynamics in turbulent times-access to higher education for refugees in Europe. Studies in Higher Education, 45(2), 327338. https://doi.org/10.1080/03075079.2018.1525697

Lambrechts, A. A. (2020). The super-disadvantaged in higher education: Barriers to access for refugee background students in England. Higher Education, 80(5), 803-822. https://doi.org/10.1007/ s10734-020-00515-4

Lenette, C., Baker, S., \& Hirsch, A. (2019). Systematic policy barriers to meaningful participation of students from refugee and asylum-seeking backgrounds in Australian higher education. In J. L. Mc Brien (Ed.), Educational Policies and Practices of English-Speaking Refugee Resettlement Countries (pp. 88-109). Leiden: Brill. https://doi.org/10.1163/9789004401891_004

Mangan, D., \& Winter, L. A. (2017). (In)validation and (mis)recognition in higher education: The experiences of students from refugee backgrounds. International Journal of Lifelong Education, 36(4), 486-502. https://doi.org/10.1080/02601370.2017.1287131

Molla, T. (2020). Refugees and equity policy in Australian higher education. Policy and Reviews in Higher Education, 5(1), 5-27. https://doi.org/10.1080/23322969.2020.1806727

Morrice, L. (2009). Journeys into higher education: The case of refugees in the UK. Teaching in Higher Education, 14(6), 661-672. https://doi.org/10.1080/13562510903315282

Morrice, L. (2013). Refugees in higher education: Boundaries of belonging and recognition, stigma and exclusion. International Journal of Lifelong Education, 32(5), 652-668. https://doi.org/10.1080/ 02601370.2012 .761288

Naidoo, L., Wilkinson, J., Adoniou, M., \& Langat, K. (2018). Navigating Complex Spaces: Refugee Background Students Transitioning into Higher Education. Springer.

Naidoo, L., Wilkinson, J., Langat, K., Adoniou, M., Cunneen, R., \& Bolger, D. (2015). Case study report: Supporting school-university pathways for refugee students' access and participation in tertiary education. Penrith, NSW: University of Western Sydney. Retrieved 20 August 2021 from https:// researchdirect.westernsydney.edu.au/islandora/object/uws:28637/.

O'Shea, S. (2016). Avoiding the manufacture of "sameness": First-in-family students, cultural capital and the higher education environment. Higher Education, 72(1), 59-78. https://doi.org/10.1007/ s10734-015-9938-y

Perry, K. H., \& Mallozzi, C. A. (2011). “Are you able ... to learn?”: Power and access to higher education for African refugees in the USA. Power and Education, 3(3), 249-261. https://doi.org/10.2304/ power.2011.3.3.249

Phillips, J. (2017). Australia's humanitarian program: A quick guide to the statistics since 1947. Parliamentary Library Research Paper series. Canberra, ACT: Parliament of Australia, Department of Parliamentary Services. Retrieved 24 August 2021 from https://parlinfo.aph.gov.au/parlInfo/downl oad/library/prspub/3599552/upload_binary/3599552.pdf.

Ramsey, G., \& Baker, S. (2019). Higher education and students from refugee Backgrounds: A meta-scoping study. Refugee Survey Quarterly, 31(1), 55-82. https://doi.org/10.1093/rsq/hdy018

RCOA (Refugee Council of Australia). (2019). Who is a refugee? Who is an asylum seeker? [Refugee Council of Australia website, 26 December; online article]. Retrieved 13 December 2020 from http://www.refugeecouncil.org.au/getfacts/international/definitions/who-are-asylum-seekers/.

Stevenson, J., \& Baker, S. (Eds.). (2018). Refugees in higher education: Debate, discourse and practice. Emerald Publishing.

Stevenson, J., \& Willott, J. (2007). The aspiration and access to higher education of teenage refugees in the UK. Compare: A Journal of Comparative and International Education, 37(5), 671-687. https:// doi.org/10.1080/03057920701582624

Streitwieser, B., Brueck, L., Moody, R., \& Taylor, M. (2017). The potential and reality of new refugees entering German higher education: The case of Berlin institutions. European Education, 49(4), 231-252. https://doi.org/10.1080/10564934.2017.1344864

Unangst, L., Ergin, H., Khajarian, A., DeLaquil, T., \& de Wit, H. (2020). Refugees and Higher Education: Trans-National Perspectives on Access, Equity and Internationalization. Leiden: Brill/Sense. 
UN (United Nations). (2015). Transforming our world: The 2030 Agenda for sustainable development. New York: United Nations. Retrieved 23 August 2021 from https://sustainabledevelopment.un.org/ post2015/transformingourworld/publication.

UNHCR (United Nations High Commissioner for Refugees). (2006). Persons of concern to UNHCR. In UNHCR and international protection: A protection induction programme (pp. 17-32). Geneva: UNHCR. Retrieved 24 August 2021 from https://www.unhcr.org/44b5005c2.pdf.

UNHCR. (2011). The 1951 Convention relating to the status of refugees and its 1967 protocol. Geneva: UNHCR. Retrieved 20 December 2020 from https://www.refworld.org/docid/4ec4a7f02.html.

UNHCR. (2017). Left behind: Refugee education in crisis. Geneva: UNHCR. Retrieved 26 January 2021 from https://www.unhcr.org/uk/events/conferences/59c4bd3b7/behind-refugee-education-crisis. $\mathrm{html}$ ?query=left $\% 20$ behind.

UNHCR. (2019). Refugee education 2030. A strategy for refugee inclusion. Geneva: UNHCR. Retrieved 21 December 2020 from https://reliefweb.int/sites/reliefweb.int/files/resources/71213.pdf.

UNHCR. (2020). UNHCR's Refugee data finder [online database]. Geneva: UNHCR. Retrieved 20 December 2020 from https://www.unhcr.org/refugee-statistics.

Universities Australia. (2017). Australia's education exports at record high (Universities Australia online media release, 3 February). Retrieved 16 May 2018 from https://www.universitiesaustralia.edu.au/ media-item/australias-education-exports-at-record-high/.

Webb, S., Dunwoodie, K., \& Wilkinson, J. (2019). Unsettling equity frames in Australian universities to embrace people seeking asylum. International Journal of Lifelong Education, 38(1), 103-120. https://doi.org/10.1080/02601370.2018.1559891

World Bank. (2020). School enrolment, tertiary (\% gross) [online database, using data as of provided by the UNESCO Institute for Statistics (UIS)]. Washington, DC: The World Bank. Retrieved 21 December 2020 from https://data.worldbank.org/indicator/SE.TER.ENRR.

Publisher's Note Springer Nature remains neutral with regard to jurisdictional claims in published maps and institutional affiliations.

Susan Webb, PhD, became Professor (Adjunct) of Education at Monash University, Australia (on retirement in 2020). Prior to working in Australia, she was Professor of Continuing Education at the University of Sheffield, UK. Her research focuses on social justice and equity in the access and participation of students, including migrants and refugees, in further and higher education. Recent projects include: the Australian Research Council Discovery Project DP170101885 - "Vocational institutions, undergraduate degrees: distinction or inequality?"; and a longitudinal qualitative study of the higher education experiences of people from asylum-seeking backgrounds. She is also Co-Editor of the International Journal of Lifelong Education.

Karen Dunwoodie, $\mathrm{PhD}$, is currently working as the deputy director and research fellow at the Deakin Centre for Refugee Employment, Advocacy, Training and Education (CREATE). She has worked, volunteered, researched, and advocated in the refugee sector in Australia for the past 10 years and her research interests include progressing the field of refugee resettlement, principally focusing on career development and the impact access to tertiary education and training may have on the lives of refugees and people seeking asylum. Current research projects include investigating career (re)construction for people from refugee and asylum-seeking backgrounds and the role of the mentee-mentor relationship.

Jane Wilkinson, PhD, is Professor of Educational Leadership in the Faculty of Education, Monash University, Australia. She researches educational leadership for social justice focusing on youth of refugee origin in schools, universities and everyday learning spaces. Jane's most recent research with/for youth of refugee origin has examined and theorised (1) the trajectories of asylum-seeking students in higher education and what enables and inhibits their retention; and (2) ecologies of educational practices that foster educational achievement for young people of refugee background with a particular focus on understanding achievement through the eyes of the learner.

Luke Macaulay, $\mathrm{PhD}$, is a research fellow at Deakin University's Centre for Refugee Employment, Advocacy, Training, and Education (CREATE). As an interdisciplinary researcher, Luke has worked in a 
number of areas including: higher education, educational leadership, inclusive education, refugee and migration studies, and cultural studies. Luke's current research explores cultural experiences of becoming an adult and the social/political belonging of refugee background youth.

Kristin E. Reimer, PhD, is a lecturer in Monash University's School of Education, Culture and Society, where she works to advance the idea of education as a humanising practice. Restorative Justice Education (RJE), the main focus of Kristin's work, is one such humanising approach in schools. With RJE, educators focus on building strong relationships in schools and rigorous, healthy learning environments. Beyond RJE, other threads of Kristin's research and practice reinforce education as a connective endeavour: alternative education for justice-involved youth; access to higher education for non-traditional students; experiences of refugee and asylum-seeking university students; global citizenship education; and intergenerational teaching relationships.

Mervi Kaukko, PhD, is an Associate Professor in Multicultural Education at Tampere University's Faculty of Education and Culture in Finland and an adjunct fellow at Monash University, Australia. Originally a primary school teacher, Kaukko currently conducts participatory and arts-based research with refugee-background children and youth in Finland and Australia. Kaukko is interested in issues of social justice in education as well as practice theories and participatory methods. Currently, Kaukko explores refugee students' educational achievements and relational well-being. Her research has been published in English and Finnish in journals such as Refugee Studies, Childhood, Educational Action Research and YOUNG

\section{Authors and Affiliations}

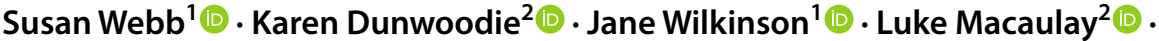 Kristin E. Reimer ${ }^{1}$ (1) Mervi Kaukko ${ }^{3}$}

Karen Dunwoodie

k.dunwoodie@deakin.edu.au

Jane Wilkinson

jane.wilkinson@monash.edu

Luke Macaulay

L.macaulay@deakin.edu.au

Kristin E. Reimer

Kristin.reimer@monash.edu

Mervi Kaukko

mervi.kaukko@tuni.fi

1 School of Education, Culture \& Society, Faculty of Education, Monash University, Clayton, VIC, Australia

2 Faculty of Business and Law, Deakin University, Burwood, VIC, Australia

3 Faculty of Education and Culture, Tampere University, Tampere, Finland 